\title{
Bringing Engineering Design into High School Science Classrooms: The Heating/Cooling Unit
}

\author{
Xornam S. Apedoe $\cdot$ Birdy Reynolds \\ Michelle R. Ellefson - Christian D. Schunn
}

(C) Springer Science+Business Media, LLC 2008

\begin{abstract}
Infusing engineering design projects in K-12 settings can promote interest and attract a wide range of students to engineering careers. However, the current climate of high-stakes testing and accountability to standards leaves little room to incorporate engineering design into K-12 classrooms. We argue that design-based learning, the combination of scientific inquiry and engineering design, is an approach that can be used to meet both K-12 educators' and engineering advocates' goals. This paper describes an 8-week high school curriculum unit, the Heating/Cooling System, in which engineering design is used to teach students central and difficult chemistry concepts such as atomic interactions, reactions, and energy changes in reactions. The goals of the paper are to (1) describe this successful designbased unit, (2) provide guidelines for incorporating designbased learning into other science topics, and (3) provide some evidence of its value for teaching difficult chemistry concepts and increasing interest in engineering careers.
\end{abstract}

Keywords Design-based learning · Inquiry-based learning $\cdot$ High school science $\cdot$ Project-based learning

Recent trends suggest a significant decline in the number of $\mathrm{K}-12$ students interested in careers in the fields of science, technology, engineering and mathematics (STEM) (van

X. S. Apedoe $(\bowtie) \cdot$ B. Reynolds · C. D. Schunn

Learning Research \& Development Center, University

of Pittsburgh, 3939 O'Hara St, Pittsburgh, PA 15260, USA

e-mail: xapedoe@pitt.edu

M. R. Ellefson

Department of Psychology, Virginia Commonwealth University, 806 West Franklin St, P.O. Box 842018, Richmond, VA 23284, USA
Langen and Dekkers 2005). The total number of math, engineering and physical science majors has been declining since the mid-1980s (Mooney and Laubach 2002). Unlike other disciplines, engineering lacks a formal presence in $\mathrm{K}$ 12 education (Cunningham et al. 2007), sharply decreasing students' opportunities to engage in work that is authentic to the daily lives of engineers. Recently, there have been efforts to incorporate engineering experiences into classroom practice. Design projects have been used to motivate and teach science in elementary, middle, and high-school classrooms and can serve to open doors to possible science or engineering careers (Sadler et al. 2000). We have developed design-based learning (DBL) units, which combine engineering design with scientific inquiry. The DBL units are designed to inspire a broad cross-section of high school students to want to become engineers, as well as transform their science classrooms so that they will graduate from high school with a foundation of knowledge that will allow them to do well as undergraduate engineers.

This paper describes an 8-week high school curriculum unit, the Heating/Cooling System that uses engineering design as a way to teach high school students the central and difficult chemistry concepts. Chemistry is a challenging subject in the school curriculum because it is complex and abstract. Chemistry's complexity comes from its understanding of matter at three levels of representation: macroscopic, microscopic and symbolic (Gabel 1999). It is particularly difficult to develop an intuitive understanding of the connection between the microscopic and macroscopic levels (Harrison and Treagust 2002). Additionally, students' difficulty understanding chemistry stems from the emphasis on teaching chemistry at the symbolic level (Gabel 1999). Students also have little or no motivation for understanding the symbolic formalisms used in chemistry. Gabel (1999) argues that incorporating hands-on practical 
work into the chemistry classroom is one way to make the symbolic formalisms more meaningful and strengthen the connections between the macroscopic and the microscopic.

Extending Gabel's (1999) suggestion, we argue that design-based learning is an approach that can be used to make the symbolic formalisms of chemistry more meaningful to students and provide a context that students find motivating for learning. Design-based learning is a particular form of project-based learning, which, in turn, is a form of active learning. In design-based learning the activity that is meant to promote learning is a design-project; students are required to use and extend their knowledge of science and math to develop a technological solution to a problem using available resources. Engaging students in design-based learning activities within a science classroom can help them develop problem solving skills and scientific inquiry skills (Kolodner et al. 2003a; Silk et al. 2007). In addition, prior studies have found that students engaged in design-based classrooms learned more in their scientific content knowledge compared to learning in the traditional science classrooms (Kolodner et al. 2003a; Fortus et al. 2004, 2005; Mehalik et al. 2008).

The goals of the paper are to (1) describe this designbased unit, (2) provide guidelines for teachers or researchers who are interested in incorporating designbased learning into their work, such that they are able to create their own design-based learning unit for other science topics, and (3) provide some evidence of its value for teaching difficult science concepts and increasing interest in engineering careers. This paper describes the primary features of the unit to show the factors that shaped its design and the solutions that were adopted. This unit description includes a fair amount of detail to make it clear that a large number of constraints must be met to teach (versus simply use) core science concepts in the context of a real engineering design task. The description is structured using a conceptual framework that is meant to be informative to both readers of this paper and the students that experience the unit. We conclude the paper with data collected from several field tests of the unit.

\section{The Overall Storyline of the Heating/Cooling System}

In the Heating/Cooling System unit, students are challenged to design a heating or cooling system that relies on chemical energy and meets a personal need in their own life. Students work in teams as they go through a design process to create a prototype of their system. This process is akin to the process used by engineering designers. The unit guides the students through three main parts: Planning the Design, The Subsystems, and Presenting the Design (Fig. 1).

\section{Planning the Design}

Students begin the unit by reading about and discussing the invention and design of the Dyson ${ }^{\mathrm{TM}}$ vacuum. This activity allows students to become familiar with key design ideas
Fig. 1 Heating/cooling system unit storyline

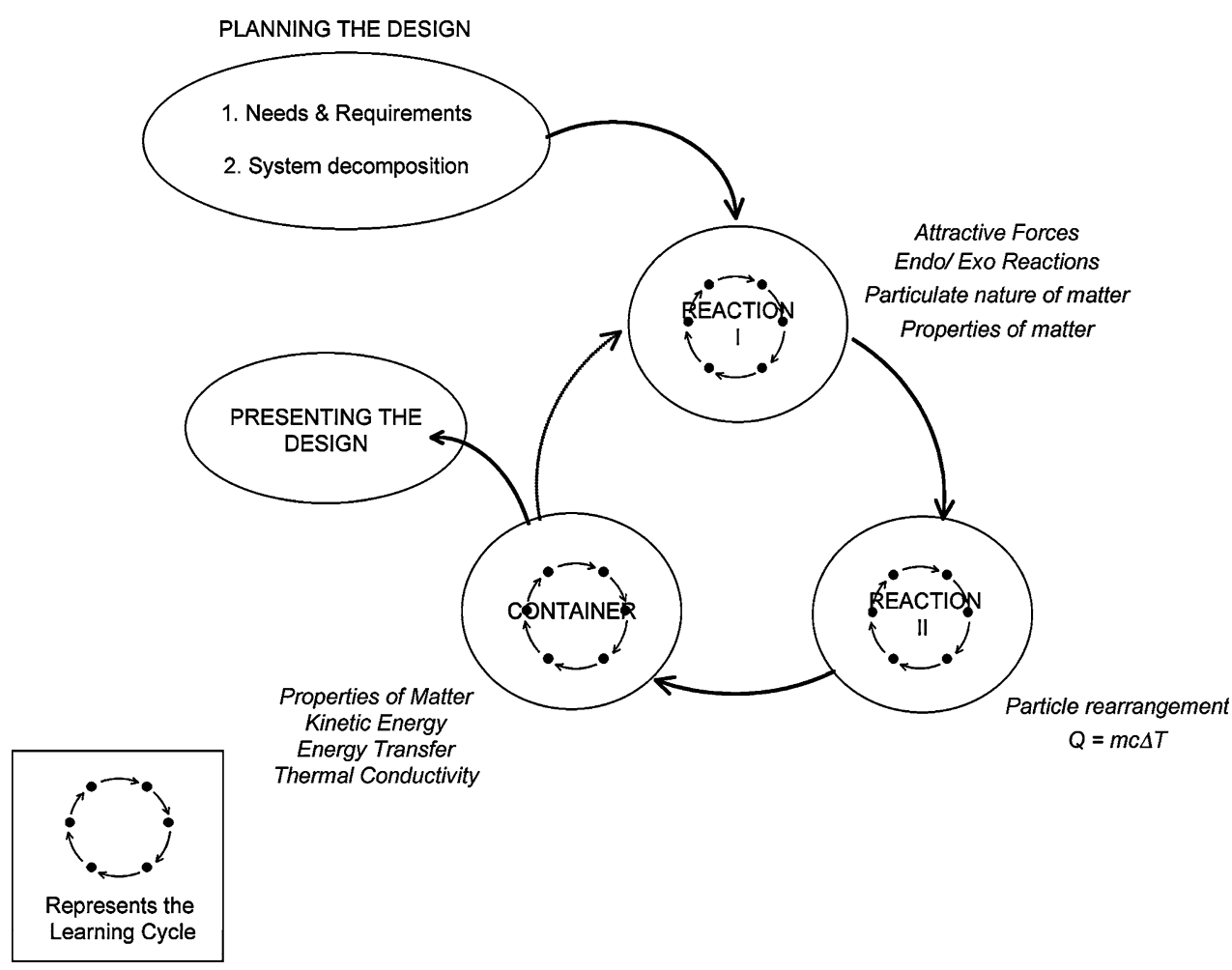


such as needs (problems that require a solution), requirements and functional decomposition. In addition, students become familiar with the context that they will work during the subsequent weeks as designers. Finally, this activity helps students recognize engineering design as a process that happens in the real world, often with the goal of redesigning and improving an everyday product to meet a need.

With this background, students work in groups to brainstorm about their needs for a heating or cooling system. Focusing on needs from their own lives creates a personal motivation for the design work, makes the topic relevant across ethnicity, gender, and other student micro-cultures, and makes salient how science and technology is a part of students' everyday lives. Students find many creative needs that connect clearly to their own lives. For example, during the unit, students set goals to create systems that would: (1) help keep them cool in the summer when they are playing sports outside, (2) prevent them from having to sit on a cold toilet seat, and (3) keep them cool when on a date and things start to 'heat up.' Once the team reaches consensus for a need they would like to meet, then they brainstorm ideas for heating or cooling systems that they could create to meet their need. See Table 1 for examples of student designs.

The next step in their design process is to think about other examples of heating or cooling systems from their everyday lives to suggest common solution methods and to consider the parts of heating/cooling systems that are essential for making them work. This activity helps students recognize that systems can be broken down into components, or subsystems, each with a special function. Subsystem decomposition is critical to the process of engineering design (Bradshaw 1992; Ulrich and Eppinger 2004). In addition, subsystem decomposition allows for coordination across the various projects in the class and some control over what chemistry concepts will be important. In this way, each team can work on a different design, while all students struggle with roughly the same deeper chemistry concepts in approximate synchrony. This method is immensely useful for sharing chemistry knowledge across teams and for helping the teacher know what concepts to emphasize across the class at a particular point in time. Although actual heating and cooling systems tend to have more than two subsystems, the conceptual focus and the time available for the unit require that students are directed towards a particular twosubsystem decomposition: the Reaction subsystem (that is responsible for producing the energy in their system) and the Container subsystem (that is responsible for managing the transfer of energy in their system).

\section{The Subsystems}

During the unit, students spend most of their time working within the reaction and container subsystems. Because this part of the unit is most important for learning of chemistry concepts, the unit attempts to go through this part more slowly and thoroughly than the other two phases (Planning the Design and Presenting the Design). The Reaction subsystem (Reaction I \& II), and the Container subsystem address different, chemistry concepts and multiple passes through the same subsystem allow students to gain a deeper understanding of the relevant concepts (e.g., adding more advanced concepts or moving from a qualitative understanding to a quantitative understanding).

It is important to note that each subsystem addresses one Big Idea. The Big Idea allows us to tie the target concepts together in ways that are conceptually relevant, as well as relevant for the designs. In each lesson, students engage in activities that allow them to grapple with one or two key concepts. The lessons are arranged such that the knowledge developed in each lesson is reinforced and built upon in subsequent lessons, culminating in the synthesis of all the concepts encountered in the final lesson of the subsystem called Connecting to the Big Idea. Table 2 outlines the target key concepts and Big Idea addressed in each subsystem for the Heating/Cooling System unit. The key concepts as listed in Table 2 are presented at a level appropriate for a teacher rather than for students. When implementing the unit, teachers are encouraged to discuss

Table 1 Examples of Student Designs for Heating/Cooling systems

\begin{tabular}{|c|c|c|}
\hline $\begin{array}{l}\text { Prototype } \\
\text { name }\end{array}$ & Purpose of design & Design specifications \\
\hline $\begin{array}{l}\text { Stay Cool } \\
\text { Water Bed }\end{array}$ & To get a good night's sleep when it's hot out & $\begin{array}{l}\mathrm{NaHCO}_{3} \text { and } \mathrm{HCl} \text { enclosed in metal pipes to cool the water in the bed to } \\
19.5^{\circ} \mathrm{C} \text {. }\end{array}$ \\
\hline Instant Ice & $\begin{array}{l}\text { To chill foods or slow frozen foods from melting (i.e., } \\
\text { Ice cream, popsicles, soda) }\end{array}$ & $\begin{array}{l}\mathrm{NaHCO}_{3} \text { and } \mathrm{HCl} \text { cools an enclosed space to } 9^{\circ} \mathrm{C} \text {. Inside the insulating } \\
\text { shell the chemicals would cool the food. }\end{array}$ \\
\hline Warm Robe & To warm you up quickly, if you are chilled & $\begin{array}{l}\mathrm{LiCl} \text { and water in a plastic bag is velcroed into the back of the robe, } \\
\text { raising the temperature to } 40^{\circ} \mathrm{C} \text {. }\end{array}$ \\
\hline Coola Coasta & A beverage coaster that keeps your drink cold longer & $\begin{array}{l}\mathrm{LiCl}, \mathrm{KBr} \text {, and } \mathrm{HCl} \text { mixed in a metal container cooled the surface to } \\
11^{\circ} \mathrm{C} \text {. }\end{array}$ \\
\hline Warmtastic & To keep hands nice and toasty when it's cold outside & $\begin{array}{l}\text { Plastic packets containing } 1.26 \mathrm{~g} \mathrm{LiCl} \text { and } 10 \mathrm{~mL} \text { water are placed into } \\
\text { gloves and warms them to } 46^{\circ} \mathrm{C} \text {. }\end{array}$ \\
\hline
\end{tabular}


Table 2 Big ideas and key concepts for each subsystem

\begin{tabular}{ll}
\hline Subsystem \& Big Idea $\quad$ Key concepts \\
\hline
\end{tabular}

\section{Reaction I}

Energy released or absorbed during chemical transformations is dependent on the shape and structure of the particles involved in the transformation.

\section{Reaction II}

Energy released or absorbed during chemical transformations is dependent on the mass and temperature change in the system.

\section{Container}

Energy transfers from particles with high kinetic energy to particles with lower kinetic energy through collisions.

- Matter is made up of particles that have mass and occupy space.

- Particles have a unique composition. The composition of particles determines their physical and chemical properties.

- Particles interact with each other; this interaction may result in an increase or decrease in temperature.

- Exothermic reactions are measured by an increase in the temperature of the system. Endothermic reactions are measured by a decrease in the temperature of the system.

- The composition of particles determines how they interact with each other.

- Interactions are the attraction between particles. Interactions between particles may result in transformations.

- Transformations involve changes in attractions between particles.

- Generally, as the size of the cation/anion increases the final temperature of the reaction involving the rearrangement of these ions will be lower.

- Higher energy levels are related to the size of the cation/anion.

- The size of the cation/anion is directly related to the distance to the nucleus and the attraction of the valence electrons of one nucleus to another nucleus.

- Mass affects the amount of energy in the system.

- An increase in mass results in more particle interactions, and consequently increases the energy of the system.

- The mass of a reactant affects the change of temperature of the system.

- All reactions have a specific maximum amount of energy.

- Increases/decreases in mass are not directly proportional to increases/ decreases in temperature.

- Changes in temperature are directly proportional to changes in energy.

- The container is made up of particles that have unique composition that determines how they interact with the environment.

- Conduction is the mechanism by which energy is transferred when two objects are in contact.

- Thermal conductivity is the transfer of kinetic energy through conduction.

- Thermal conductivity is a unique property of matter.

- The atomic mass and structure of a substance affect its ability to transfer energy between adjoining atoms.

- Substances that transfer heat energy quickly are called conductors.

- Substances that transfer heat energy slowly are called insulators.

these key concepts using language that is appropriate for the level of students in their course.

\section{Carefully Chosen Chemistry Concept Targets}

A primary goal of the unit is to teach particular chemistry concepts. The concept targets of the Heating/Cooling System unit were very carefully chosen. Specifically, we identified concepts having high value in chemistry as well as having high leverage with chemistry teachers. We defined high value concepts as conceptually central to the science discipline: they explain many phenomena (e.g., many reaction types), they are used in many disciplinary activities (e.g., in synthesis and analysis), and they are the foundation of many later topics. Such concepts are ones we need to teach well. We defined concepts as high leverage with chemistry teachers and school district administrators when the concepts are recognized as very important within the curriculum (e.g., found on state or other high stakes tests, or match beliefs about importance), yet are very 
difficult for students to learn and the foundation for subsequent learning. We sought concepts for this unit that were both high value and high leverage because they increase teachers' and administrators' openness to new curriculum materials; there is little value for designing a unit that few people are willing to try.

In the Heating/Cooling System unit, students consider both chemical and physical (dissolution) reactions. The unit included the three core high value and high leverage chemical concepts: atomic interactions, reactions and energy changes during reactions (see Table 2). These concepts are related to each other conceptually because chemistry, at its core, can be said to be about the properties and reactions of substances (Taber and Coll 2002). Unfortunately, students have difficulty understanding how and why reactions occur. Students have difficulty understanding why reactions occur primarily because at the high school level there is little discussion of the causal explanations for reactions, leaving students in an 'explanatory vacuum' (Taber and Coll 2002). Understanding how reactions occur requires an understanding of atomic interactions; however, atomic interactions are a difficult concept for students because they often have naïve conceptions about the particulate nature of matter (Harrison and Treagust 2002). Finally, energy is an important concept as it relates to reactions because consideration of reaction energy allows one to predict the outcome of chemical processes (Goedhart and Kaper 2002). It is well documented that students have difficulty using and understanding reaction energy concepts (Goedhart and Kaper 2002).

In addition to these concepts being foundational to chemistry and difficult for students to understand, teachers often struggle to teach these concepts (Yaron et al., unpublished manuscript). However, atomic interactions, reactions, and energy changes in reactions are core in the national and state standards, and thus teachers must spend time addressing these concepts. This combination of factors makes the implementation of the Heating/Cooling System unit attractive to teachers because it meets many of their needs.

\section{The Learning Cycle}

The activities inside each subsystem are structured in a common way. For each of the subsystems, students follow a cycle from design goals to science goals and back to design goals. Throughout this cycle, there are whole class discussions, team activities, and individual activities created to maximize learning of science content as well as learning design and science processes. Thus, this cycle can be called the design-science cycle or the learning cycle, and is similar to the legacy cycle developed by Bransford and colleagues (Brophy and Bransford 2001). For this paper, we refer to the cycle as the Learning Cycle.
The purpose of repeatedly going through a commonly structured process is for students to learn and practice important science and design skills that they will use at increasingly higher performance levels across the unit and transfer to later classroom practice after the unit is completed (Kolodner et al. 2003a). Learning cycles have been advocated by other learning scientists for effective classroom learning (e.g., Karplus 1977; Lawson et al. 1989; Novick and Nussbaum 1981). The particular version of a Learning Cycle that is found in the unit was developed to (1) include systematic scientific investigation to make especially salient to students the core scientific concepts and the data that support them, (2) use the design context to motivate particular scientific questions, (3) connect the scientific investigations to the overall design story such that the motivational advantages of the design task are not lost, and (4) integrate the advantages of teamwork and whole class discussions.

Each cycle (and subsystem) begins at the Create Design node and proceeds clockwise through the cycle, leaving the subsystem after the Connect to Big Idea node. As shown in the diagram (Fig. 2), science and design activities overlap in the Public Dialogue space. The activities that occur in the Public Dialogue space are ones that take place at a class level, thus encouraging sharing and discussion of ideas between students and the teacher. The discussions and revisions of student conceptions about chemistry during the Public Dialogue foster new insights for students about how they might use chemistry ideas to improve their design.

Students begin the Learning Cycle in the Design space at the Create Design node. Here, students develop a design idea and try it out. Students make observations of how their design worked in the Evaluate Outcome node. Reasons for the outcomes they observe are discussed as a class during Generate Reasons. Here, students address questions such as: Was my design successful? If yes, what factors were

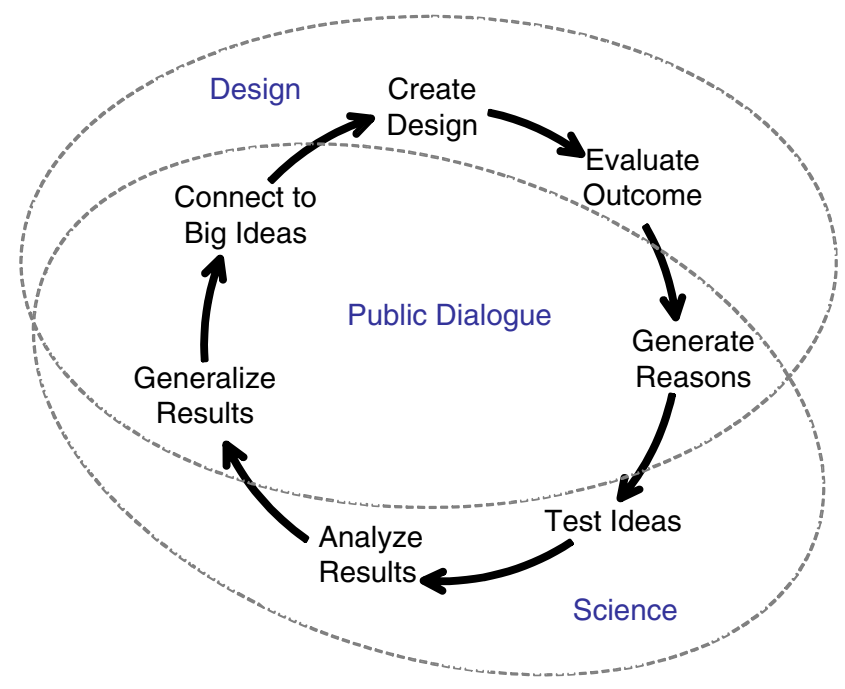

Fig. 2 Learning Cycle 
important for the success of the design? If no, what factors may have influenced the failed performance of the design? Students propose ways to systematically test some of their generated reasons and conduct these tests during Test Ideas. From there, students analyze the results from their experiments in Analyze Results. They discuss the results as a class during Generalize Results to uncover a pattern, theory, or trend. Finally, students arrive at Connect to Big Idea, where they link their design to the key science concept(s) that can be used to improve its performance. Overall, the Learning Cycle is structured to maintain a motivating design storyline while preventing students from wasting time floundering and encouraging students to focus attention on the selected core concepts. It is important to note that the activities that students engage in at each node of the Learning Cycle are designed to begin by eliciting the ideas and understanding currently held by students. For meaningful learning to occur, instruction should begin with an exploration of learners' interpretations and understandings of the science concepts to be addressed (Taber 2003). A specific example of how the Learning Cycle is used in the Heating/Cooling System unit is provided below.

\section{The Reaction Subsystems}

From the Planning the Design activities, students enter Reaction I with a requirement for a specified temperature, e.g., 'we require a reaction that reaches five degrees Celsius' and a specific peak 'reaches temperature in $30 \mathrm{~s}$.' It is important that the students are pushed to include serious/ difficult-to-achieve requirements. If all of the requirements are met easily, then there is no need to learn the underlying science to support the overarching design process.

In the Create Design node of the Learning Cycle, students can use a variety of chemicals (mostly salts) that, when combined with water, produce endothermic or exothermic reactions. Salts were chosen because they met safety and cost constraints while still revealing important periodic trends through relatively large temperature differences across various combinations. In the Evaluate Outcomes node, students evaluate the outcomes of their trials by noting temperature changes and whether their temperature requirement was met. Students Generate Reasons (which are essentially causal hypotheses) for why they obtained the recorded outcomes. One of the reasons that students often generate is: "My reaction did not get hot because I used the wrong combination of chemicals." This very simple reason is a launching point into the Test Ideas node, where students think of ways to test one of the reasons in ways that relate to chemistry-relevant properties. In Reaction I, students are guided to think of ways to test the idea: the composition of the reactants, i.e., cation vs. anion, affects the final temperature of the system. In the Test
Ideas node, students conduct a systematic test of the effect of the cation and anion on the final temperature of the system. Students collect and record their data so that during the Analyze Results node they can construct graphs and tables that will help them analyze their results. Students share their results with the rest of the class in the Generalize Results node so that the students can begin to recognize meaningful patterns in the class' data. Finally, in the Connect to Big Idea node, a class discussion guides students to understand the Big Idea for Reaction I, i.e., energy released or absorbed during chemical transformations is dependent on the shape and structure of the particles involved in the transformation. Students learn about bond energies (and lattice energies) and consider the enthalpy changes that have occurred in the reactions they have observed.

During Reaction II, students are given the opportunity to apply what they have learned about chemical transformations, the particulate nature of matter, etc. to the design of their Reaction subsystem. Again, students follow the Learning Cycle and build on their knowledge about the concepts encountered in Reaction I, while thinking about particle rearrangement and energy changes in reactions. The Big Idea that is the culmination of the activities and investigations in Reaction II is that energy released or absorbed during transformations is dependent on the mass and temperature change in the system. Students are introduced to the mathematical equation $Q=m c \Delta T$ as an example of how scientists use equations to derive theoretical values, in this case the energy of a system, that can also be derived experimentally.

At the end of Reaction II, students refine the design of their Reaction subsystem using what they have learned from Reaction II. For example, students might adjust the amounts of chemicals to create the amount of energy needed for their system. Finally, students calculate the heat of reaction for their chosen reaction. Once students have chosen a reaction to serve as the energy source, then they move on to the Container subsystem.

\section{The Container Subsystem}

At the end of Reaction II, students begin to think about their reactions as more than just meeting their temperature requirement, but as subsystems that produce energy to affect some other object. Building on this idea, in the Container subsystem, students are challenged to think about how different container materials will affect the transfer of energy from their Reaction subsystem. Students are provided with a number of basic materials, (e.g., polystyrene; metals strips such as copper, aluminum, brass, nickel and steel; polyethylene-terephalate), as well as a Material Sheet that contains information about important properties of the materials such as density, thermal 
conductivity, melting point, specific heat, etc. These materials were chosen for cost and accessibility reasons, while at the same time revealing important trends in thermal conductivity and energy transfer as a consequence of the materials' properties.

In the Create Design node of the Learning Cycle, students try various container materials to determine which material allows for sufficient transfer of energy between their reaction and some other object. Students Evaluate the Outcome of these trials and Generate Reasons for why they believe the different materials did not allow for sufficient transfer of energy. During the class discussion, teachers guide students toward thinking that thermal conductivity is a unique property of matter with important implications for their design. In the Test Ideas node, students conduct a systematic test of thermal conductivity and then calculate relative thermal conductivities and insulation properties of the various container materials in the Analyze Results node. Students present their results to the rest of their class in the Generalize Results node and attempt to recognize meaningful patterns from the class' data. Finally, in the Connect to Big Idea node, a class discussion guides students to understand the Big Idea for the Container subsystem: Energy transfers from particles with high kinetic energy to particles with lower kinetic energy through collisions.

At the end of Container, students refine their design using what they have learned. Here, students may choose to use different materials (e.g., copper rather polystyrene), a different combination of materials (e.g., copper and polystyrene), or a different arrangement of materials (e.g., copper on the inside and polystyrene on the outside) after having learned about the mechanism and direction of energy transfer and the material properties that affect energy transfer.

\section{Presenting the Design}

Students end the unit by putting together a final prototype of their design to present to their peers during a Gallery Walk (Kolodner et al. 2003a, b). The Gallery Walk simulates a poster session at a scientific or engineering conference. Students are expected to discuss both the design (i.e., "Why this design?") and science (i.e., "How does it work?") aspects of their prototype. Finally, students complete a Patent Application, detailing the specifications of their design and how it works scientifically. Both the final prototype and patent application allow students to refine and connect their science and engineering knowledge.

\section{Why Focus on Heating/Cooling?}

Part of the difficult work in developing this type of curriculum is choosing an appropriate design task. We argue that two criteria are essential. Firstly, the task must be relevant to students' lives. Using a task that has personal relevance to students will encourage student ownership and increase student excitement and interest in science. The Heating/Cooling System is such a design task because students are able to posit a number of design possibilities that can connect to their everyday needs.

Secondly, careful consideration must be given to the materials. Design is a hands-on process that necessitates the use of materials for prototypes and working models. When developing the Heating/Cooling System unit, we chose materials that were both inexpensive (so they could be replenished by school districts with small science budgets) and allowed for robust science learning. In other words, the science patterns need to be reliable and measured easily with these materials; the requirements need to be obtainable with these materials; it must be hard (hence requiring science understandings) to meet the requirements with only random choices. In the Heating/Cooling System, the chemical space consists mostly of salts and weak acids that are inexpensive but still allow students to productively struggle with the target concepts that are the basis of the unit.

\section{Implementation}

We have conducted field trials of this Heating/Cooling System unit for the past 3 years with approximately 1,400 students, including high-needs urban high schools with 99\% minority students and more average suburban high schools. The classroom types included Honors/Advanced Chemistry students, typical Chemistry I students, and Spectrum Science students. These successful field trials with teachers and students in urban, high-need settings showed the power of this type of approach for teaching difficult chemistry concepts to high school students. Based on teacher reports and our own classroom observations, many students demonstrate high levels of engagement. During a professional development session, teachers gave the following observations about their students:

Teacher 1: ...Some of the kids actually want a final product perfect and working at the end.

Teacher 2: That's what I'm saying. Some of them really, really want to have something. They think they're earning patents!

Teacher 3: They actually think that people at [the university] are going to steal their ideas.

Also, during our many classroom observations we noted students' curiosity about the chemistry concepts they were learning. For example, in one classroom a student team was developing a Heating Mug. They had already created an exothermic reaction and knew the standard definition of 
both exothermic and endothermic reactions. During one classroom visit, we challenged this team's definition of an exothermic reaction by asking, "Why does the temperature increase if exothermic reactions release energy?" Initially the students looked dumbfounded and could not produce a logical response. However, during our next class visit, the students approached us and declared that they had researched our question and now had an answer.

As another measure of student interest, teachers have reported they have students who have had dismal attendance prior to beginning the unit, but who then attend every class period while the unit is being implemented.

\section{Study 1: Impact on Chemistry Knowledge}

In addition to the observations about the unit, pre-unit and post-unit assessments were administered to measure student understanding of atomic interactions, reactions, and energy changes in reactions. The five (four female, and one male) teachers who participated in this study were part of a cohort of 8 teachers who implemented the design-based learning unit and attended professional development sessions related to the unit. Of the five participating teachers, three teachers had prior experience with design-based learning and had implemented a previous version of the unit. All of the participating teachers taught and implemented the unit in at least two classes or sections of chemistry.

A total of 380 high school students participated in some part of the design-based learning unit. They were 9th, 10th, 11th and 12th grade high school students enrolled in spectrum science, general chemistry, or advanced general chemistry courses. Despite classroom type, this was the first year of chemistry coursework for the students. Accounting for absences and school transfers, a total of 271 students completed the unit and both the pre- and post-unit assessments.

The assessment comprised 24 questions taken from the Chemical Concept Inventory (CCI) (Mulford 1996) and the American Chemical Society's (ACS) Test Item Bank for high school chemistry (Eubanks and Eubanks 1993). The $\mathrm{CCI}$ is a multiple choice assessment instrument that contains non-mathematical conceptual questions that tap into student's understanding of chemical ideas. Many of the questions include representation at the macroscopic, microscopic (particulate) and symbolic level. Questions from the CCI were selected because they assess reasoning skills and common naïve conceptions. However, the CCI includes topics not typically covered until a first-year college level chemistry course. Students who have completed one semester of college level chemistry had an average score of $50 \%$ on the CCI (Division of Chemical Education 2008). Thus, it was expected that these questions would be difficult for the high school students and that analyses might be difficult if scores were low enough to encounter floor effects.
Additional, more factual, questions were selected from the ACS test bank based on their relevance to the Heating/ Cooling System unit. The ACS Test-Item Bank was developed to provide high school instructors with assessment items for first-year chemistry courses, thus it was expected that the selected questions would be at a difficulty level appropriate for the students. Sample test items from both the $\mathrm{CCI}$ and the ACS Test Bank are provided in the Appendix.

Overall, the assessment measure was useful considering that various school constraints prevented implementation of this unit until March in the cohort that was tested. With nearly two-thirds of the academic year completed, students had experience with all of these concepts before the beginning of the unit and yet their pre-test performance indicated that they had failed to learn most of these core concepts from 6 months of instruction. Would a 6- to 8 -week intervention be enough to matter?

Scores on the assessments were subjected to a repeatedmeasures ANOVA (analysis of variance) and Cohen's $d$ (Cohen 1997) was used to compute effect size. The results indicated that students' had a $13 \%$ accuracy gain for 24 questions related to the unit concepts, $F(1,270)=27.65$, $p<.0001, d=.31$. Accuracy increased for all concepts, with $21 \%$ gains for the atomic interactions questions, $F(1$, $270)=12.56, p<.001, d=.25,12 \%$ gains for the reactions questions, $F(1,270)=7.60, p<.01, d=.18$, and $14 \%$ gains for the energy changes during reactions questions, $F(1,270)=9.55, p<.01, d=.23$ (See Fig. 3).

One general concern about hands-on or inquiry activities is that students do not learn the underlying science concepts through these activities as well as they would have learned the same material though direct instruction (Kirschner et al. 2006). This concern is particularly troublesome because teachers frequently report having too little time to cover the required concepts. Although the unit takes 68 weeks to complete, our teachers have reported to us that they have been able to cover more content after completing our unit compared to previous years because students have a stronger grounding in the core ideas of chemistry.

\section{Study 2: Impact on Engineering Interest}

In addition to helping students learn fundamental chemistry concepts, learning about design and engineering is an intended outcome of this curricular approach. As part of a larger evaluation project, data was collected from 79 students who completed the Heating/Cooling System unit regarding their interest and awareness of engineering. We compared these students to 58 of their peers (in the same school) who did not complete the Heating/Cooling System unit in their chemistry classroom. Students rated on a Likert scale (1-5) how much they agreed with statements that related to their interest and awareness of engineering. 


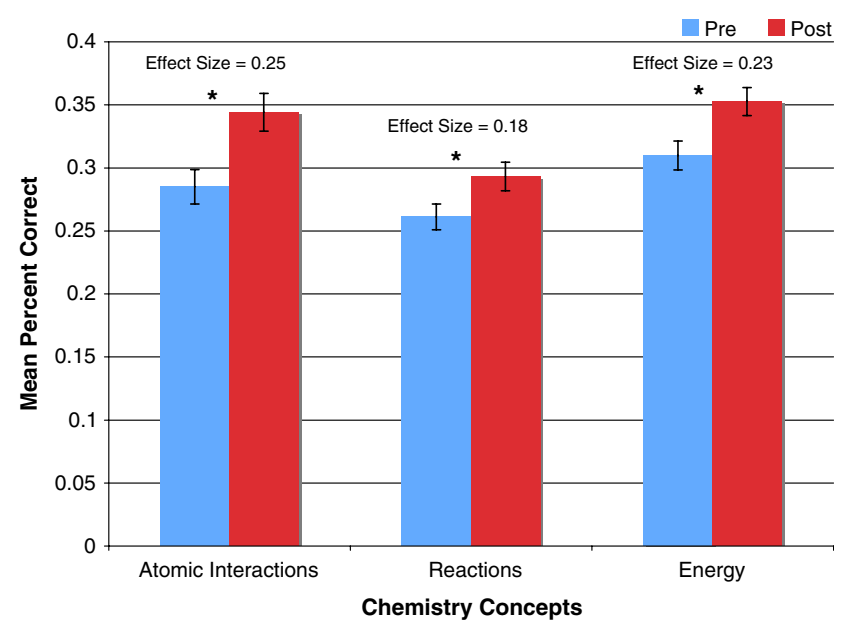

Fig. 3 Student performance on chemistry concepts

Data was analyzed along four important dimensions: (1) knowledge of engineering as a career; (2) desire to be an engineer; (3) desire to take additional classes related to designing for problem-solving; and (4) desire to participate in after-school or summer engineering technology experiences. These dimensions are important because they directly relate to many of the reasons students cite for not considering engineering as a potential career.

The results indicate that students who completed the Heating/Cooling Systems unit in their chemistry classroom were more likely than their non-participating peers to agree with the statement "I want to be an engineer," $t(135)=2.82$, $p=0.01 ; d=.49$. In addition, students who experienced the unit in their classrooms tended to show more agreement with the statements: "I know what engineering is," "I would like to take classes that let me design products that solve problems," and "I would like to participate in after-school or summer engineering technology experiences," although these differences were not statistically significant (Fig. 4).

\section{Results Summary}

One of the goals of the Heating/Cooling Systems unit was to help students learn difficult, core concepts in chemistry. The study reported here suggests that students made significant gains towards understanding the fundamental concepts of atomic interactions, reactions, and energy during the unit. As the mean scores on the post-tests were low, there is room for improvement. However, seeing significant gains on core content so late in the academic year (after months of traditional instruction) is promising. Finally, students' increased interest in engineering careers suggests that exposure to engineering design in the context of high school science is an effective way to encourage students to consider engineering as a viable career option. Follow-up studies on the long-term interest of engineering careers might be useful for better

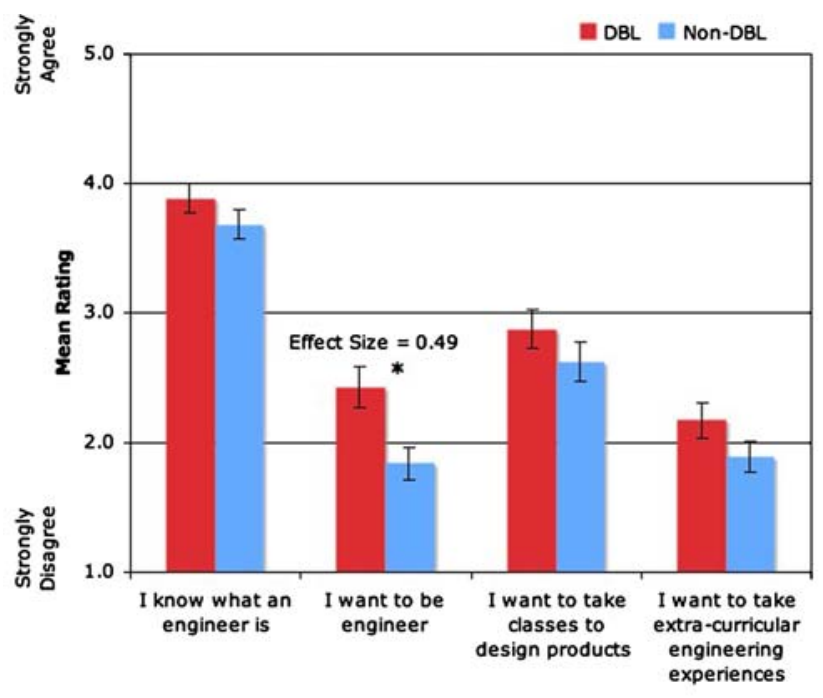

Fig. 4 Comparison of engineering interest

understanding which experiences encourage students to pursue their interest in engineering.

\section{Relationship to Existing Chemistry Curricula}

Reform curricula are standards-based and grounded in contemporary studies of teaching and learning. At the middle school level, there are a variety of curricula that utilize inquiry-based, Science \& Technology Concepts for Middle Schools: Properties of Matter (National Science Resource Center 2000); project-based, Fraud (Wright 2005); laboratory-based, Foss: Chemical Interactions (FOSS 2008); or technology-based, Web-based Inquiry Science Environment (WISE) (Slotta, 2004), approaches to instruction. Currently, there are very few reform curricula targeted specifically for high school chemistry. The existing curricula are year-long programs. Chemistry in the Community (American Chemical Society 2006) uses a problem-based approach to introduce chemistry concepts that are related to community issues. Active Chemistry (Freebury et al. 2006) uses a project-based approach to teach important chemistry concepts. Living by Chemistry (Stacy 2005) uses a student-centered approach to facilitate regular exchanges of ideas through interactive discussions amongst students and between students and instructors.

Although there are some similarities in the goals and methods of these reform curricula and the Heating/Cooling System unit, there are some important features that make the Heating/Cooling System unit unique. One important feature that we would like to highlight is that students learn the chemistry concepts while engaged in design. Rather than learning all the relevant chemistry concepts and then applying them to a design challenge, in the Heating/ 
Cooling System unit, the design drives the science that is to be learned and the science that is learned directly impacts the modifications made to the design. In addition, although the unit is not a yearlong curriculum, when implemented early in the school year, teachers can revisit the concepts addressed in the unit throughout the rest of the year.

\section{Relationship to Existing Design-Based Curricula}

Our design-based curricula builds on work done by several other groups (e.g. Learning by Design (LBD), Kolodner et al. 2003a; Design-Based Science (DBS), Fortus et al. 2004, 2005; and Stuff that Works!, Benenson and Neujahr 2002) that focus on the use of design in the classroom. While each of these curricula are similar in that they use of design as a framework for scaffolding science learning, each has adopted different methods to do so. Benenson and Neujahr's (2002) Stuff that Works! is designed to engage elementary students in the core ideas and processes of engineering. While students may utilize important math or science concepts while engaged in the design activities, learning about the core concepts of engineering (content, process and social practice) is the focus of the Stuff that Works! curriculum. In contrast, Kolodner and colleague's (2003a) Learning by Design curriculum, is targeted to teach middle school students important concepts in physical and earth science. The goals of the LBD curriculum are to (1) engage all learners, (2) help students learn important reasoning and social skills while learning content, and (3) learn both science content and skills well enough to be able to apply them in new situations (Kolodner et al. 2003a). Designing, in the LBD curriculum, refers to the range of activities that professional designers from a variety of disciplines including, but not limited to, engineering, architecture, and industrial design undertake to achieve a design challenge. Thus, design is construed in its much broader sense of the term in the LBD curriculum. Finally, the DBS (Fortus et al. 2004, 2005) curriculum aims to engage 9th grade students in design activities to help them construct scientific understanding and real-world problemsolving skills. Much like our goals for the Heating/Cooling Systems unit, the DBS units that have been developed are not meant to be a culminating experience where students apply the scientific knowledge that they have learned, but rather, all new scientific knowledge and problem-solving skills are developed in the context of designing artifacts (Fortus et al. 2005).

\section{Conclusion}

The unit may be useful for those teachers and researchers interested in finding more effective approaches to teaching high school chemistry and expose students to engineering before they make decisions about whether to go to university and what to study. Our work provides a demonstration proof that design-based learning can be effective for teaching and learning difficult core concepts in chemistry, as well as increasing awareness and interest in engineering. Also, we have provided theoretically-derived insights into likely factors for high rates of implementation and successful student outcomes. Like all designed artifacts, this unit can likely be improved as well as adapted to other goals. The detailed description of the framework and reasoning behind the framework is provided to facilitate further work with this approach.

Acknowledgements This material is based upon work supported by the National Science Foundation under Grants EEC-0502035 and EHR-0227016. Any opinions, findings, and conclusions or recommendations expressed in this paper are those of the authors and do not necessarily reflect the views of the National Science Foundation.

\section{Appendix}

Chemical Concept Inventory Sample Item 1

The diagram represents a mixture of $\mathrm{S}$ atoms and $\mathrm{O}_{2}$ molecules in a closed container.

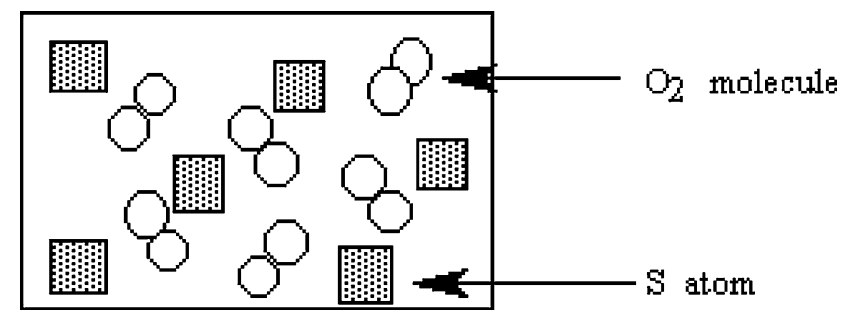

Which diagram shows the results after the mixture reacts as completely as possible according to the equation:

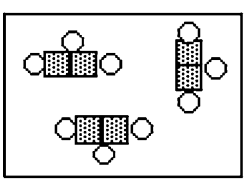

(a)

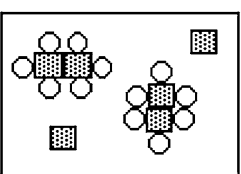

(b)

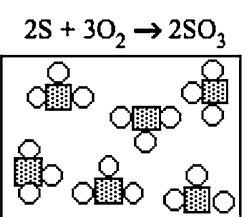

(c)

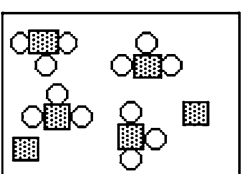

(d)

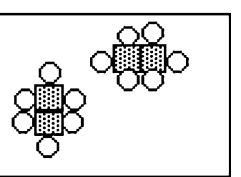

(e) 
Chemical Concept Inventory Sample Item 2

$100 \mathrm{~mL}$ of water at $25^{\circ} \mathrm{C}$ and $100 \mathrm{~mL}$ of alcohol at $25^{\circ} \mathrm{C}$ are both heated at the same rate under identical conditions. After $3 \mathrm{~min}$ the temperature of the alcohol is $50^{\circ} \mathrm{C}$. Two minutes later the temperature of the water is $50^{\circ} \mathrm{C}$. Which liquid received more heat as it warmed to $50^{\circ} \mathrm{C}$ ?
a. The water.
b. The alcohol.
c. Both received the same amount of heat.
d. It is impossible to tell from the information given.

What is the reason for your answer to the question above?

a. Water has a higher boiling point than the alcohol.

b. Water takes longer to change its temperature than the alcohol.

c. Both increased their temperatures $25^{\circ} \mathrm{C}$.

d. Alcohol has a lower density and vapor pressure.

e. Alcohol has a higher specific heat so it heats faster.

\section{ACS Sample Item 1}

In any chemical reaction energy is
a. Always absorbed.
b. Always released.
c. Released as heat.
d. Usually not involved.
e. Either absorbed or released.

\section{ACS Sample Item 2}

When $\mathrm{KCl}$ dissolves in distilled water, which of the following, other than water molecules, are in the solution?
a. $\mathrm{KCl}$ molecules.
b. $\mathrm{K}$ and $\mathrm{Cl}$ atoms.
c. $\mathrm{K}^{+}$and $\mathrm{Cl}^{-}$ions.
d. $\mathrm{KCl}^{-}$ions.

\section{References}

American Chemical Society (2006) Chemistry in the community, 5th edn. W. H. Freeman \& Co, New York

Benenson G, Neujahr JL (2002) Stuff that works! A technology curriculum for the elementary grades. Heinemann, Portsmouth

Bradshaw GF (1992) The airplane and the logic of invention. In: Gidere RN (ed) Cognitive models of science. University of Minnesota Press, Minneapolis

Brophy SP, Bransford JD (2001) Design methods for instructional modules in bioengineering. In: Proceedings of the 2001 American Society of Engineering Education. http://vanth.org/ Publications.html. Accessed 14 March 2008
Cohen EG (1997) Restructuring the classroom: conditions for productive small groups. In: Dubinksy E, Matthews D, Reynolds $\mathrm{BE}$ (eds) Readings in cooperative learning for undergraduate mathematics. Mathematical Association of America, Washington DC

Cunningham CM, Knight MT, Carlsen WS, Kelly G (2007) Integrating engineering in middle and high school classrooms. Int J Eng Educ 23(1):3-8

Division of Chemical Education, American Chemical Society (2008) Conceptual questions: chemical concept inventory. http:// jchemed.chem.wisc.edu/JCEDLib/QBank/collection/ CQandChP/CQs/ConceptsInventory/CCIIntro.html. Accessed 13 April 2008

Eubanks ID, Eubanks LP (1993) ACS test-item bank for high school chemistry. American Chemical Society Division of Chemical Education Examinations Institute, Milwaukee

Fortus D, Dershimer RC, Krajcik J, Marx RW, Mamlok-Naaman R (2004) Design-based science and student learning. J Res Sci Teach 41(10): 1081-1110

Fortus D, Krajcik J, Dershimer RC, Marx RW, Mamlok-Naaman R (2005) Design-based science and real-world problem solving. Int J Sci Educ 27(7):855-879

FOSS Chemical Interactions (2008) http://scienceview.berkeley.edu/ chemicalinteractions/. Accessed 31 October 2007

Freebury G, Gromko M, Heltzel C, Roeder J, Sevian H, Smith S, Tennesand M (2006) Active chemistry, 2nd edn. Its About Time, Armonk

Gabel D (1999) Improving teaching and learning through chemistry education research: a look to the future. J Chem Educ 76:548554

Goedhart MJ, Kaper W (2002) From chemical energetics to chemical thermodynamics. In: Gilbert JK, De Jong O, Justi R, Treagust DF, Van Driel JH (eds) Chemical education: towards research-based practice. Kluwer Academic Publishers, Boston, pp 339-362

Harrison AG, Treagust DF (2002) The particulate nature of matter: challenges in understanding the submicroscopic world. In: Gilbert JK, De Jong O, Justi R, Treagust DF, Van Driel JH (eds) Chemical education: towards research-based practice. Kluwer Academic Publishers, Boston, pp 189-212

Karplus R (1977) Science teaching and the development of reasoning. J Res Sci Teach 14:167-175

Kirschner PA, Sweller J, Clark RE (2006) Why minimal guidance during instruction does not work: an analysis of the failure of constructivist, discovery, problem-based, experiential, and inquiry-based teaching. Educ Psychol 41:75-86

Kolodner JL, Camp PJ, Crismond D, Fasse B, Gray J, Holbrook J, Puntambekar S, Ryan M (2003a) Problem-based learning meets case-based reasoning in the middle-school science classroom: putting learning by design into practice. J Learn Sci 12(4):495-547

Kolodner JL, Gray J, Fasse BB (2003b) Promoting transfer through case-based reasoning: rituals and practices in learning by design classrooms. Cogn Sci Q 3:183-232

Lawson A, Abraham M, Renner J (1989) A theory of instruction: using the learning cycle to teach science concepts and thinking skills, 1st edn. National Association for Research in Science Teaching, Manhattan

Mehalik MM, Doppelt Y, Schunn CD (2008) Middle-school science through design-based learning versus scripted inquiry: better overall science concept learning and equity gap reduction. J Eng Educ 97(1):1-15

Mooney M, Laubach TA (2002) Adventure engineering: a designcentered, inquiry-based approach to middle grade science and mathematics education. J Eng Educ 91(3):309-318

Mulford DS (1996) An inventory for measuring college students' level of misconceptions in first semester chemistry. Unpublished Master's Thesis, Purdue University, IN 
National Science Resource Center (2000) Science \& technology concepts for middle schools: properties of matter, 1st edn. Carolina Biological Supply Co., Burlington

Novick S, Nussbaum J (1981) Pupil's understanding of the particulate nature of matter: a cross age study. Sci Educ 65:187-196

Sadler PM, Coyle HP, Schwartz M (2000) Engineering competitions in the middle school classrooms: key elements in developing affective design challenges. J Learn Sci 9(3):299-324

Silk EM, Schunn CD, Strand Cary M (2007) The impact of an engineering design curriculum on science reasoning in an urban setting. In: Proceedings of the National Association for Research in Science Teaching, New Orleans, LA, USA, 15-17 April 2007

Slotta JD (2004) The Web-based Inquiry Science Environment (WISE): scaffolding knowledge integration in the science classroom. In: Linn MC, Davis EA, Bell P (eds) Internet environments for science education. Lawrence Erlbaum Associates, Mahwah, NJ, pp 203-232
Stacy AM (2005) Living by chemistry: teaching more students standards-based chemistry, 1st edn. Key Press, Emeryville

Taber KS (2003) Mediating mental models of metals: acknowledging the priority of learner's prior learning. Sci Educ 87:732-758

Taber KS, Coll RK (2002) Bonding. In: Gilbert JK, De Jong O, Justi R, Treagust DF, Van Driel JH (eds) Chemical education: towards research-based practice. Kluwer Academic Publishers, Boston, pp 231-234

Ulrich KT, Eppinger SD (2004) Product design and development, 3rd edn. McGraw-Hill/Irwin, Boston

van Langen A, Dekkers H (2005) Cross-national differences in participating in tertiary science, technology, engineering and mathematics education. Comp Educ 41(3):329-350

Wright RG (2005) Fraud: a event-based science module, 1st edn. Pearson Prentice Hall, Upper Saddle River 